\title{
An analysis of health seeking behaviour on utilization of skilled delivery services by Maasai women in kiekonyokie sub location of kajiado county in Kenya
}

\author{
Lebahati Simel L. ${ }^{1}$, Nanduri L. ${ }^{2}$, A. Juma P. ${ }^{3}$, O. Omuga B. ${ }^{\text {* }}$ \\ DOI: https://doi.org/10.17511/ijphr.2017.i5.06 \\ 4* Lakshmi Nanduri, Associate Professor, School of Public Health, Asmara College of health Science, Asmara, Eritrea, East Africa.
}

1 Laban Lebahati Simel, Lecturer, School of Public Health, Asmara College of health Science, Asmara, Eritrea, East Africa.

2 Pamela A. Juma, Director Great Lakes University of Kisumu, Nairobi Campus, Nairobi, Kenya.

3 Blasio O. Omuga, Lecturer, University of Nairobi, Nairobi, Kenya.

Introduction: Maternal health is one of the eight Millennium Development Goals, is central to poverty reduction and overall development, and it increased international attention for monitoring progress on maternal health and improving access to skilled attendants at deliveries. In Kenya, 44 percent of births are delivered under the supervision of a health professional, mainly a nurse or midwife. Objectives: This research paper aimed to analyse the role of Health Seeking Behaviour on the utilization of skilled delivery services by Maasai women, the study population belonging to a community of nomadic life style in North of Kajiado County in Kenya. Methodology: The study design was a cross sectional descriptive study adopting both quantitative and qualitative methodologies. The sample size was 264 women of reproductive age obtained by using formula given by Fisher et al., when the population is more than 10,000 . The quantitative data has been analyzed using (SPSS) version 17.0 while the qualitative data was analyzed by summarizing of the themes. Results: Results show that 57.2\% Maasai women go to the health facility in case of illnesses, while $7.6 \%$ consulted their mother in law., husbands make most of the decisions (40.2\%) on the place of delivery of the expectant mothers whereas as the relatives make the least decisions $5.7 \%$. Preparation of the expectant mother for delivery did not have a statistical significant $p$ 0.046. The traditional rite of passage practices had no statistical significance $p-0.190$. $72 \%$ of womencould mention at least one correct danger sign for pregnancy out of the posssible four.

Keywords: Maasai Women, Health Seeking Behaviour, Utilization of Skilled Delivery Services, Kajiado County, Kenya

Corresponding Author

Lakshmi Nanduri, Associate Professor, School of Public Health, Asmara College of health Science, Asmara, Eritrea, East Africa.

Email: nlakshmi2@rediffmail.com
How to Cite this Article

Simel LL, Nanduri L, Juma PA, Omuga BO. An analysis of health seeking behaviour on utilization of skilled delivery services by Maasai women in kiekonyokie sub location of kajiado county in Kenya. Public Health Rev Int J Public Health Res. 2017;4(5):134-140.

Available From

https://publichealth.medresearch.in/index.php/ijphr/ article/view/74
Manuscript Received 2017-11-28

Conflict of Interest No

Review Round 1
2017-12-08
Funding
Nil

Review Round 1 $\mathrm{Nil}$

Review Round 2
2017-12-16
$\begin{gathered}\text { Ethical Approval } \\ \text { Yes }\end{gathered}$

Review Round 3

Plagiarism X-checker $8 \%$
To Browse

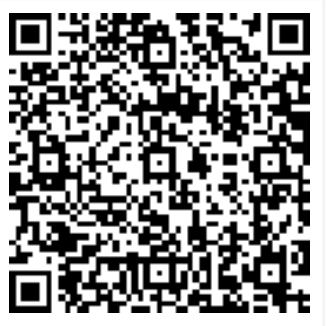

(c) 2017 by Laban Lebahati Simel, Pamela A. Juma, Blasio O. Omuga, Lakshmi Nanduri and Published by Siddharth Health Research and Social Welfare Society. This is an Open Access article licensed under a Creative Commons Attribution 4.0 International License https://creativecommons.org/licenses/by/4.0/ unported [CC BY 4.0].

Accepted 2017-12-21

Note 


\section{Introduction}

The identification of maternal health as one of the eight MDGs firmly situates it as central to poverty reduction and overall development efforts. Its inclusion has resulted in increased international attention for monitoring progress on maternal health and improving access to skilled attendants at deliveries as a key indicator for measuring progress for Goal 5 [1].

Current estimates of maternal mortality ratios vary from more than 1000 per 100,000 live births in most African countries, to around 500 in some Asian countries, to between 200-400 in South America and fewer than 10 in developed countries.

In developing countries, specifically in sub Saharan countries, many women don't have the good fortune to be attended by skilled personnel during child birth, most childbirth occurs at home and is not assisted by skilled attendants, this lack of skilled attendance could be considered as one of the major factors in maternal and infantile mortality [2].

The Cairo International Conference on Population and Development [3] placed a lot of emphasis on reproductive health of which safe motherhood is a component. Kenya adopted the plan of action on /reproductive health.

The government recognized the right of access to appropriate health care services that will enable women to safely go through pregnancy and child birth and provide couples with best chance of having healthy infants. It is every woman's right to access high quality maternal health services that in turn must be accessible, affordable, effective, appropriate and acceptable to them in order to avoid preventable morbidity and mortality [4].

Many complications of pregnancy and child birth that lead to mortality can be prevented by providing quality care that involves early detection of problems and appropriate timely interventions [5]. Skilled attendants may perform deliveries either at home, in health centres or in hospitals, but it is argued that the most efficient strategy is to place them in health centres with referral capacity [5].

In Kenya, 44 percent of births are delivered under the supervision of a health professional, mainly a nurse or midwife. Traditional birth attendants continue to play a vital role in delivery, assisting with 28 percent of births.
The 2008-09 KDHS found that two out of five births, 43 percent are delivered in a health facility, while 56 percent are delivered at home. Relatives and friends assist in 21 percent of births. The proportion of births assisted by medically trained personnel increased slightly since 2003.

Maternal mortality ratio for the 10 -year period before the survey was estimated at 488 maternal deaths per 100,000 live births. This was statistically insignificantly different from the rate of 414 maternal deaths per 100,000 live births for the tenyear period prior to the $2003 \mathrm{KDHS}$.

Births in urban areas and births to mothers who have more education, wealth are more likely to be assisted by medical personnel than those births to mothers who reside in rural areas or who have less education and no wealth. Regional variations in type of assistance at delivery are also pronounced, with Western province recording the 26 percent of births assisted by medical professionals, followed by North Eastern province, 32 percent.

Nairobi has the highest proportion of births assisted by medical personnel 89 percent. 32 percent of births in North Eastern province are attended by a skilled provider, only 17 percent occur in a health facility and it is the only province in Kenya where a sizeable proportion of births are attended by skilled providers at home. The proportion of births assisted by medically trained personnel has increased marginally from 42 percent in 2003 to 44 percent [6].

Kajiado County is within the Rift Valley Province and it is located in the Southern part of the Province. It borders the Republic of Tanzania to the Southwest, Taita Taveta County to the Southeast, Nairobi City to the Northeast, Kiambu County to the North and Narok County to the West.

The county covers an area of approximately $21,902.9 \mathrm{Km} 2$ and is divided into 7 wards namely: Ngong, Magadi, Isinya, Central, Namanga, Mashuru and Loitokitok. It has five constituencies namely: Kajiado North, Kajiado East, Kajiado West, Kajiado Central and Kajiado South. Kajiado has two local authorities namely: Olkejuado county Council and Kajiado Town Council [7].

The population of women of reproductive age (1549 years) in Kajiado County in 2002, which is approximated to be $25 \%$ of the total population, was 110,548 in 2002 and was projected to rise to 218,547 by the year 2020 . 
The challenge has therefore remained the provision of Maternal Child Health/Family Planning services to cater for the health needs of the expanding number of women of reproductive age. Nevertheless, in Kajiado county, different aspects of provision of reproductive health services are still found to want [7].

The county has 3 county Hospitals, 19 health centers, 40 dispensaries, 26 private health institutions and the average distance to a health facility is 10 Kilometres. The most prevalent diseases are malaria, respiratory infections, diarrhoea, skin diseases and eye infections. The doctor/patient ratio is $1: 66,412$.

Life expectancy level in the District is 43 years, which is below the national average of 53 years. The county has experienced difficulties in providing efficient health services for the fast-growing population because it needs heavy investments to upgrade, modernize and construct new health facilities [7].

The prevalence of home deliveries in some parts of Kajiado County is as high as $77.8 \%$ [8]. The proportion of mothers assisted by traditional birth attendants during delivery is equally high at $56.7 \%$. This poses a high risk to both the mother and new born [8].

Despite Kajiado District having 145 health facilities, several problems affecting skilled delivery utilization exists. The county is predominantly Maasai pronounce for their strong culture and traditions including female genital mutilation which can pose grave danger to the women during childbirth and especially if unattended by a skilled attendant.

It is noted that Maasai's have unique economic, social, cultural and environmental characteristics which could play a role in that respect as well as the level of knowledge, attitude, practice and their perception towards modern health facilities.

No substantive study has related these to utilization in delivery services in Kajiado North [7]. The numbers of home deliveries at the National level are of $56 \%$ compared to $77.8 \%$ within the county despite the existence of public health facilities.

This study therefore aimed to analyse the role of health seeking behaviour on utilization of skilled delivery services by Maasai women in Kiekonyokie sub location of Kajiado County.

\section{Methodology}

Study Design: This was a descriptive crosssectional study that applied quantitative and qualitative research methods of data collection to analyse health seeking behaviour on skilled delivery services utilization among the Maasai women in Kiekonyokie ward in Kajiado North. The quantitative data was captured through an individual questionnaire while the qualitative data was through focused group discussions and the key informant interviews.

Map of Kajiado County by Courtesy of Central Bureau of statistics 2010.

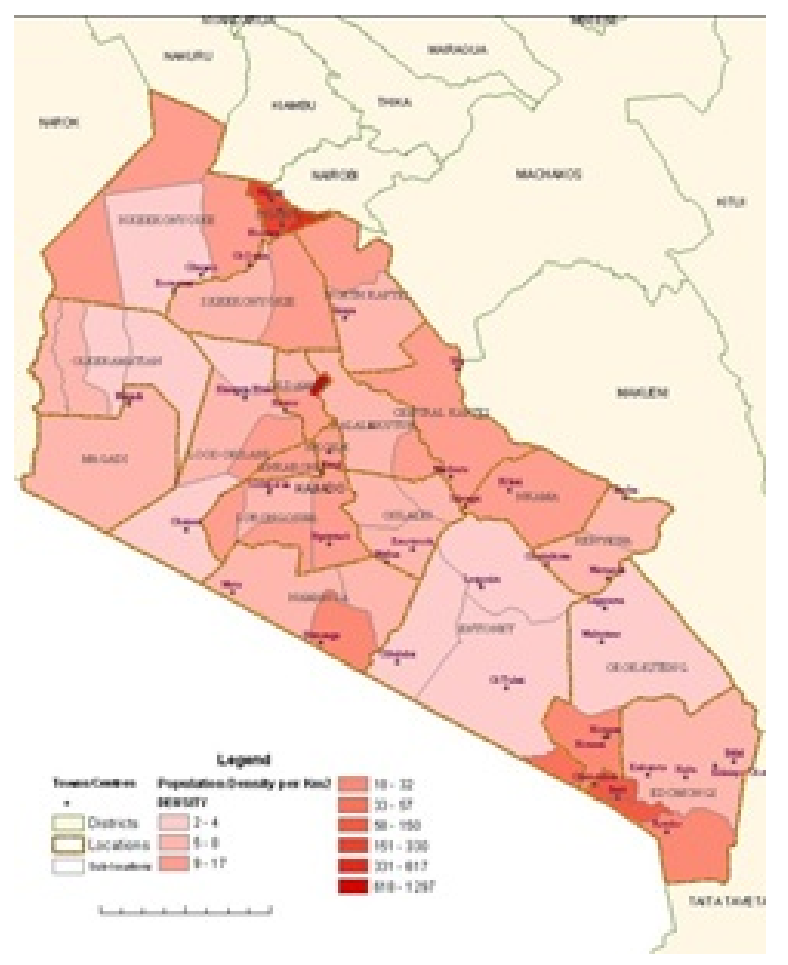

Study Population: The study population were women of child bearing age 15-49 years in Kiekonyokie ward of Kajiado County. Target populations were all women who had had a baby in the past 5 years prior to the research. The study targeted a population of women of child bearing age (15-49) years and delivered a child in the last 5 years.

Sample size determination: To compute the required sample size, Fisher's et. al,2003 formula with a confidence interval of $95 \%$ and a degree of accuracy 0.05 were used. The probability of finding a woman who has had delivery of a child in the last 5 years was not known therefore a probability of $50 \%$ shall be used. 
The population of Maasai women of reproductive age (15-49) years in Kajiado county was more than 10,000 .

$\mathrm{N}=$ desired sample size $($ pop $>10,000)$

$Z=$ normal standard deviation (1.96)

$\mathrm{P}=$ proportion of population with target characteristics/observations

$\mathrm{Q}=$ proportion without the attribute of interest (1-p)

$\mathrm{D}=$ degree of accuracy $(0.05)$

$\mathrm{N}$-sample size for population above 15,636 and households of 3133

$Z=1.96$ (Standard deviation at 95\% significance interval)

P- Prevalence of assisted deliveries $22.2 \%$

D2-0.052(Standard error at $95 \%$ confidence interval)

Therefore;

$N=\underline{1.962 \times 0.78 \times 0.22}$

0.052

$=\underline{0.6592}$

0.0025

$=\underline{6592}$

2

$=264$

264 women were included in the study.

The Sampling strategy: Systematic random sampling was used whereby the total number of women listed $(n)$ were then divided by the total number of the proportionate allocation $(\mathrm{N})$ which gave the interval of the interviews. The number obtained usually known as the Kth unit was added to the random number obtained and created the interval.

The village elder assisted in identifying all women numbered from $1-K$ th within the village who had had a baby in the past five years. Proportionate allocation was applied in distributing sample size over the villages. The community guides helped to ensure that the women were interviewed after obtaining their verbal or written consent.

In case a household selected didn't have the targeted respondent;
It was substituted by the nearest household's cconsidering women in the pastoralist community are out their houses most of day, enumerators collected data for 3 consecutive days starting early morning, the teachers, community health workers and the local chief assisted to create awareness in advance in most of the villages. The households were selected based on a sampling interval calculated as follows;

To obtain the sampling interval, SI

$=\underline{\text { Total population }}$

Sample size $(n)$

The data collection team comprised of the enumerators, a supervisor, note-takers and a comoderator had a 2 days training on use of the tools. The training was organized and conducted in English at the sub location. They familiarized themselves with the data collection tools. Pretesting of the tools was done in the neighbouring sub location

Research tool: The survey tools were adopted from those developed by Great Lakes University of Kisumu (GLUK) normally used for conducting baseline surveys in various Counties. The questionnaire had sections divided into the number of subsections i.e. demographic determinants, economic determinants, cultural determinants, health systems determinants, knowledge, attitude and practices.

Quantitative data, semi-structured questionnaires with closed ended questions derived from the operational framework were administered. The questionnaires had a few open-ended questions. The questionnaire was pretested with the qualitative tools which are Focused Group discussion guide and Key informant interview guide in a neighbouring sub location with similar characteristics.

Qualitative Methods: The tools for qualitative data collection comprised of focus group discussion tool, key informant interview tool and a manual note taking at the time of the discussions. The qualitative methods included 3 focused group discussions of women; each group had 8-12 members. The key informant interviews included the chief, facility midwives and elders. The key informant interviews were also conducted targeting opinion health resource persons from the District.

Pre-testing of research tools: After the training on the research tools, the questionnaire, the focus group discussion (FDG) guide and the key informant 
Interview guide were pre-tested in a neighbouring sub-location. Prior the actual data collection, the questionnaires were pre-tested in Kiekonyokie south location area (outside the cluster areas under study) and each enumerator had a chance to interview at least one woman who has had a child in the last 5 years.

Pre-testing was done to check on the validity, consistency, time taken, and completeness of the tool by comparing the data obtained by principal investigator versus the enumerators data and also to have enumerators familiarize themselves with the tool and also to check the ability of the interviewers and the quality of the tools. Based on the result corrections were done and harmonized.

Data collection: Quantitative data was collected using semi-structured questionnaires administered by a team of trained enumerators and supervisors. The questionnaire was segmented into sections to capture information on the specific target objectives. Questionnaires for each cluster were coded differently for easy monitoring during data collection and the enumerators were required to write their names for follow-up in case of need for a clarification.

Qualitative data was collected using focus group discussions and key informant interviews. 3 FGDs were held i.e. one in each of the cluster areas through barazas forum. The FGD participants were selected using similar criteria to the one for quantitative data collection. In each FGD there were 6 to 9 discussants who were women aged between 15 and 49 years.

The invitations were conducted through the village elders who had acted as community guides during quantitative data collection. There were 2 notetakers during the discussion. One co-moderator was engaged to take note of any non-verbal expressions that can be propped at the end of the discussion.

Data Analysis: Quantitative Data was entered into Statistical Package for Social Sciences (SPSS) software version 17.0 and further analysed using descriptive statistics including narration. Data was then presented using frequencies, graphical techniques, ratios, rates and percentages Bivariate and Univariate analysis was used to describe the correlations.

Qualitative data were analysed through content and thematic analysis.
The main themes included are health seeking behaviour, decision on the place of delivery, preparation of expectant mother, knowledge on the danger signs of pregnancy, time to reach health facility, cost paid to skilled delivery, views on the health facility staff behaviour.

\section{Results}

This study on health seeking behaviour in Maasai women showed the following results. The table 1 below shows that $57.2 \%$ went to the health facility in case of illnesses, while $7.6 \%$ consulted their mother in law.

Table-1: Health seeking behaviour

\begin{tabular}{|l|l|l|}
\hline \multicolumn{1}{|c|}{ Health seeking behaviour } & Frequency & \multicolumn{1}{c|}{ Percent } \\
\hline Seek traditional healers help & 29 & 11 \\
\hline Go to the health facility & 150 & 57.2 \\
\hline Consult my husband & 64 & 24.2 \\
\hline Inform my mother in law & 20 & 7.6 \\
\hline Total & 264 & 100 \\
\hline
\end{tabular}

From an FGD session that was supported by similar findings of the KII,s the women had the following remarks on the place of delivery,

"........Ilpayani oolimu enepuo.ingituak tenesaisai...." (" ..........Men are the ones who direct women where to go during labour........")

".........Tanaabaeki engolong naisho etaana engaputany niaa naakaatoiiu ashu ariik sipitali teneyeeu....." ("........ When that day comes for me to deliver,my mother in law will assist or take me to hospital if she wants......").

The figure 1 below, shows that husbands made most of the decisions $(40.2 \%)$ on the place of delivery on the expectant mothers whereas as the relatives, made the least decisions $5.7 \%$.

\section{Figure-1: Decision making on the place of delivery}

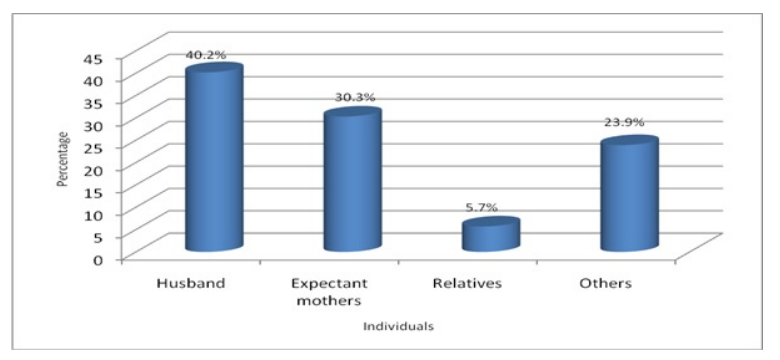

The table 2 below, shows that preparation of the expectant mother for delivery did not have a statistical significant p-0. 046. 
Table -2: Preparation of the expectant mother for delivery

\begin{tabular}{|c|c|c|c|c|c|c|}
\hline \multirow[b]{3}{*}{ Preparation of the expectant mother for delivery } & \multirow[b]{3}{*}{ Mother in law } & \multicolumn{4}{|c|}{ Hospital Births } & \multirow[t]{2}{*}{ p-value } \\
\hline & & \multicolumn{2}{|c|}{ No Utilization } & \multicolumn{2}{|c|}{ Utilization } & \\
\hline & & 98 & $71 \%$ & 40 & $29 \%$ & 0.046 \\
\hline & Husband & 61 & $86 \%$ & 10 & $14 \%$ & \\
\hline & Others & 39 & $71 \%$ & 16 & $29 \%$ & \\
\hline \multirow[t]{3}{*}{ The traditional rite of passage for the expectant mother } & None & 33 & $87 \%$ & 5 & $13 \%$ & \multirow[t]{3}{*}{0.190} \\
\hline & Female Genital Mutilation & 151 & $73 \%$ & 56 & $27 \%$ & \\
\hline & Other & 14 & $74 \%$ & 5 & $26 \%$ & \\
\hline
\end{tabular}

From an FGD session the women had the following response on skilled delivery,

".......Ore eishoi tesipitali naasidai kake meepooki ng'ai nayeu...."

(".......Delivering at the hospital is good but not everybody wants...")

The table 3 below shows $56.1 \%$, of the women had delivered at home while $11.4 \%$ were assisted by health personnel at the facility.

Table-3: Assistance during delivery

\begin{tabular}{|l|l|l|}
\hline \multicolumn{1}{|c|}{ Assistance during delivery } & Frequency & Percent \\
\hline Self (Home) & 24 & 9.1 \\
\hline Home (Assisted by relatives/Neighbours) & 148 & 56.1 \\
\hline TBA/CHW & 61 & 23.1 \\
\hline Health facility (Health personnel) & 30 & 11.4 \\
\hline Others & 1 & 0.4 \\
\hline Totals & 264 & 100 \\
\hline
\end{tabular}

The supposed correct danger signs were bleeding from the birth canal, severe head-ache, reduced foetal movements. and severe abdominal pain.

The following sentiments were captured in both FGDs and KII sessions on knowledge of danger signs,

" .......kiyolo aajo keloentua sipitali peetum embaata sidai tenotai..."

("We know that a pregnant woman should go to hospital to get good treatment during pregnancy.")

"........Ekeiteng'eni itomonok te sipitali anaapukunot naishaakinore teneeku esaisai kake Engai ooshi naatapooki naapuo sipitali o naisho tiaang..."

(".......Women are enlightened at the hospital on labour but God takes care of at the hospital and those who delivers at home.")
The figure 2 below shows that out of 264 respondents who answered this question, only $72 \%$ who could at least mention one correct danger sign for pregnancy out of the posssible four .

Figure-2: Knowledge on the danger signs.

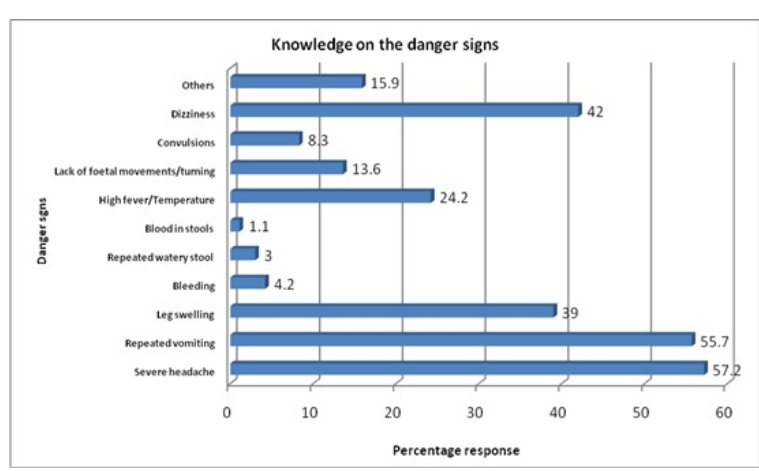

From an FGD session the women comments concurred with that of the KII findings on the issue of time taken to the nearest health facility,

".......Mikiata sipitalini kumok,nabo ake natii hooduo naakelakua ninye...." ( "......we don't have many hospitals; only one exists even though it is far away...")

".......Keya endua saai naabaya uni peebaya sipitali..." ( "......it takes an expectant woman 3hours to reach the hospital.....")

The figure 3 below indicates that (97.7\%) of the Maasai women in the Kajiado North study takes more than 1 hour to reach to the nearest health facility. Less than (1\%) of them in this study takes less than 30 minutes to reach to the health facility.

Figure-3: Time taken to the nearest health facility 


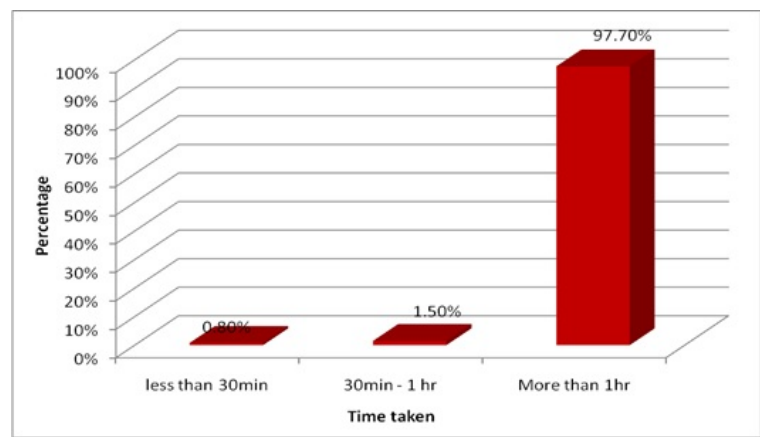

From an FGD session one of the women participant and KII expressed similar comments on the issue of staff behaviour at the facility,

"........Ore aapa abayie inasipitali naasidai embaata enye amu supati labaak..."

(".....In the past when I visited the hospital treatment was good because the care givers were polite...")

The figure 4 below shows that most of the women who visited a health facility felt that the staff behaviour was good.

\section{Figure-4: Views on the staff behaviour}

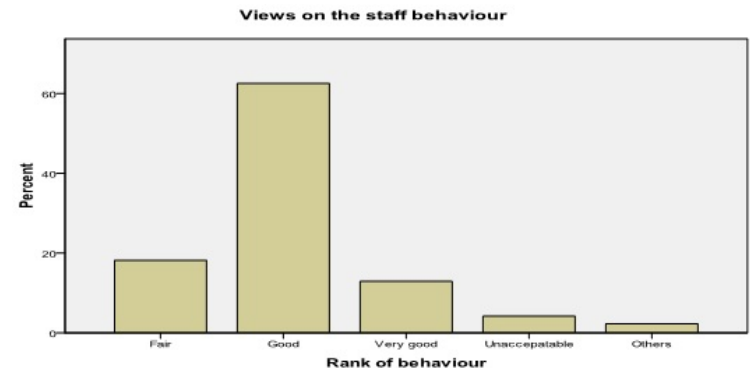

From an FGD session, some of the women made the following remarks on the cost of delivery,

"........Meeta endua impisai, ilewa oota amuninche oopuo aamirr ingishu......"(".......an expectant woman has no money; men have money because they sell livestock......" )

"........Keya negol anaa eningununo neya nelelek......"

("......At times it is expensive depending on the woman condition and sometimes it is cheap......")

The table 4 shows that among the 264 women $23.1 \%$ didn't know how much was paid for skilled delivery utilization however it came out clear during an FGD session that relative accompanying the women was responsible for payments, it also emerged that women paid for the service, independent of the place of delivery even though
There was cost variation. The cost of skilled delivery was statistically significant whereby $p=0.000$.

Table-4: Cost of skilled delivey

\begin{tabular}{|c|c|c|c|}
\hline Cost (K. Shillings) & Frequency & Percent & P-value \\
\hline No cost & 84 & 31.8 & \multirow[t]{8}{*}{0.000} \\
\hline Less than 100 & 7 & 2.7 & \\
\hline $100-500$ & 23 & 8.7 & \\
\hline $501-1000$ & 40 & 15.2 & \\
\hline Over 1000 & 34 & 12.9 & \\
\hline Don't know & 61 & 23.1 & \\
\hline Others & 15 & 5.7 & \\
\hline Total & 264 & 100 & \\
\hline
\end{tabular}

The table 5 below shows that $69 \%$ of those who delivered in the hospital paid $>500$ shillings compared to $8 \%$ of those who paid $<500$ shillings. A mount paid for skilled delivery had a statistical significance, $(p<0.001)$.

Table-5: Amount paid for skilled delivery

\begin{tabular}{|c|c|c|c|c|c|}
\hline \multicolumn{2}{|c|}{ Determinant of Skilled Delivery } & \multicolumn{2}{|c|}{ Hospital Births } & \multirow{2}{*}{ Total } & \multirow[t]{2}{*}{ p-value } \\
\hline & & $\begin{array}{l}\text { No } \\
\text { Utilization }\end{array}$ & Utilization & & \\
\hline \multirow[t]{2}{*}{$\begin{array}{l}\text { Amount in Kenyan shillings } \\
\text { paid for skilled delivery } \\
\text { services }\end{array}$} & $\begin{array}{l}<500 \\
\text { shilling } \\
\mathrm{s}\end{array}$ & $175(92 \%$ & $15(8 \%)$ & $\begin{array}{l}190(1 \\
00 \%)\end{array}$ & $<0.001$ \\
\hline & $\begin{array}{l}>500 \\
\text { shilling } \\
\mathrm{s}\end{array}$ & $23(31 \%)$ & $51(69 \%)$ & $\begin{array}{l}74(10 \\
0 \%)\end{array}$ & \\
\hline
\end{tabular}

\section{Discussion}

In Kajiado study $56.1 \%$, of the women had delivered at home while $11.4 \%$ were assisted by health personnel at the facility. $72 \%$ of the women could at least mention one correct danger sign for pregnancy out of the posssible four. The supposed correct danger signs were bleeding from the birth canal, severe head-ache, reduced foetal movements and severe abdominal pain.

These finding tends to disagree with earlier assertion in a study on use pattern of maternal health services, the proportion of women with skilled care at delivery increased with knowledge of danger signs from $39 \%$ among women who did not mention any to $68 \%$ among those who mentioned 4 or more danger signs $(p<0.005)[9]$.

The study in Kajiado showed that most of the women felt that the staff behaviour was good. This agreed with the findings made in a qualitative study in Uganda stated that, a significant proportion of mothers were reported to be delivering at their 
Homes or with Traditional Birth Attendants, they all seemed to acknowledge the benefits associated with health facility based deliveries [10].

Another finding that was in line with the Kajiado study was that done in Burkina Faso asserted that women are often surprised by the sudden onset of labour and are obliged to be attended by the traditional birth attendant or a member of the family, for some others it was not possible to know at what time the baby will come [2].

A cross sectional study on the use pattern of maternal health services and determinants of skilled care during delivery in Tanzania found out that the proportion of women with skilled attendants at delvery decreased with increasing distance to the health facility which provide delivery care from $50.1 \%$ among women residing within $5 \mathrm{~km}$ of a health facility to only $20.2 \%$ among those residing more than $5 \mathrm{~km}$ from a health facility (OR 3.84 (95\%CI 2.61-5.65) [9].

A qualitative study on women's perception of Ante Natal Care and delivery care services reveals that the costs involved in meeting hospital requirements and paying user fees and informal fees as well as meeting personal requirements, was too high, the cost of transportation, the attitude and conduct of service providers (rude and disrespectful to their clients), also deterred service utilization [10].

\section{Conclusion and Rcommendation}

In conclusion this study on health seeking behaviour shows $57.2 \%$ went to the health facility in case of illnesses, while $7.6 \%$ consulted their mother in law, preparation of the expectant mother for delivery did not have a statistical significant $p-0.046$. The traditional rite of passage practices had no statistical significance $\mathrm{p}-0.190$.

$72 \%$ who could at least mention one correct danger sign for pregnancy out of the posssible four. $69 \%$ of those who delivered in the hospital paid $>500$ shillings compared to $8 \%$ of those who paid $<500$ shillings. The amount paid for skilled delivery had a statistical significance, $(p<0.001)$.

$97.7 \%$ of the Maasai women in the Kajiado North study takes more than 1 hour to reach to the nearest health facility while less than $1 \%$ of them in this study takes less than 30 minutes to reach to the health facility. $56.1 \%$, of the women had delivered at home while $11.4 \%$ were assisted by health
Personnel at the facility and most of the women who visited a health facility felt that the staff behaviour was good.

There is need to use the community strategies to curb high levels of illiteracy in Kajiado North District and enlightening the community on the dangers of unskilled delivery service. Training of the spouses and mothers in law on the importance of facility delivery through ante natal visits and community health care workers. Develop economic programs that empower women to enable them access skilled delivery utilization.

Ethical considerations- The field work was conducted after obtaining clearance from The Great Lakes University and the National council for Science \& Technology (NTSC). Informed consent was also obtained from relevant authorities and the community in which the study was to be carried. A preparatory meeting was also held with chiefs, assistant chiefs and village elders within the broad

Cluster where the study took place. During the meeting with local leaders the objectives of the research were explained and community guides identified. The principal investigator clarified the role of the community guides during data collection.

\section{Acknowledgements}

The author greatly acknowledges the relentless cooperation of Great Lakes University of Kisumu, Kiekonyokie maasai community, Kajiado County Administrators, Yusuf Kiplagat medical data manager MSF-Nairobi, Monicah Nthumbi- program manager-AMREF-Nairobi in data collection, enumeration and statistical analysis.

\section{Reference}

01. Högberg U. The World Health Report 2005"make every mother and child count" - including Africans. Scand J Public Health. 2005;33(6)40911.

[Crossref]

02. Télesphore D Some, Issiaka Sombie and Nicolas Meda. Women's perceptions of homebirths in two rural medical Districts in Burkina Faso- a qualitative study. Licensee BioMed Central Ltd. 2011.

[Crossref]

03. The Cairo International Conference on Popu lation and Development (ICPD, 1994). 2011.

[Crossref] 
04. Lale S, Rosalind R. A systematic review of inequalities in the use of maternal health care in developing countries- examining the scale of the problem and the importance of context. WHO. 2010.

[Crossref]

05. Campbell OM, Graham WJ. Lancet Maternal Survival Series steering group, Strategies for reducing maternal mortality- getting on with what works. Lancet. 2006 Oct 7;368(9543)1284-99.

[Crossref]

06. Kenya Demographic Health Survey 2008-2009. . . 2006 Oct 7;368(9543)1284-99.

[Crossref] [PubMed] [Google Scholar] [Crossref]

07. Thomas J, et al. Kajiado District Strategic Plan 2005-2010.

[Crossref]
08. Kaseje, D, Githagui N, Masbayi A, Mulobi B. An Evaluation Report of AMREF's Ground Mobile Unit in Kajiado District, Kenya Nairobi- A publication of Assessing 50 Years Of Amref's Intervention In Kajiado District. Kenya. 2005 2010.

[Crossref]

09. Mpembeni RN, Killewo JZ, Leshabari MT, Massawe SN, Jahn A, Mushi D, Mwakipa H. Use pattern of maternal health services and determinants of skilled care during delivery in Southern Tanzania- implications for achievement of MDG-5 targets. BMC Pregnancy Childbirth. $2007 ; 6 ; 7 ; 29$.

[Crossref]

10. Ankunda R, Arinaitwe M, Ekirapa K, Bakeera $S$, Mutebi A, Kiwanuka S, Okui O, Pariyo G. 2009 Women's perceptions of ANC and Delivery Care Services- A Community Perspective. Future Health Systems Study. 2009.

[Crossref] 